\title{
Conversion and Shrinkage Analysis of Acrylated Hyperbranched Polymer Nanocomposites
}

\author{
Valérie Geiser, Yves Leterrier, Jan-Anders E. Månson \\ Laboratoire de Technologie des Composites et Polymères (LTC), Ecole Polytechnique Fédérale de Lausanne (EPFL), \\ Lausanne, CH-1015, Switzerland
}

Received 29 January 2009; accepted 18 April 2009

DOI 10.1002/app.30621

Published online 30 June 2009 in Wiley InterScience (www.interscience.wiley.com).

\begin{abstract}
The photo-curing behavior of composites containing nanosized $\mathrm{SiO}_{2}$ in an acrylated hyperbranched polymer matrix was investigated by means of photo differential scanning calorimetry. The chemical conversion data were analyzed using an autocatalytic model, paying close attention to the influence of composition and UV intensity. It was shown that the reaction order and the autocatalytic exponent were independent of UV intensity and filler fraction, whereas the rate constant showed strong intensity dependence, but weak filler dependence. Maximum conversion was independent of UV intensity,
\end{abstract}

but was reduced when a filler was present. The dispersion state influenced the gel-point of the composites, but had no influence on the overall cure kinetics. Cure shrinkage reduction of $\sim 33 \%$ could be achieved by adding $20 \mathrm{vol} \%$ of filler. This was attributed to the reduced double bond conversion of the matrix due to the presence of the filler. ( 2009 Wiley Periodicals, Inc. J Appl Polym Sci 114: 1954-1963, 2009

Key words: hyperbranched; nanocomposites; photopolymerization

\section{INTRODUCTION}

Photo-induced polymerization with UV light is an efficient method for the generation of highly crosslinked polymers from multifunctional monomers. ${ }^{1,2}$ It is used extensively for ultrafast drying of printing inks, varnishes, and protective coatings, ${ }^{2}$ the latter being utilized for the protection of virtually any substrate, such as wood, plastics, metal, glass, optical fibers, leather, paper, and fabrics. ${ }^{3}$ It has also found extensive applications for adhesives and dental restorative formulations. ${ }^{4-6}$

A drawback for UV curable formulations, and acrylates in particular, is polymerization shrinkage. In the case of coatings, the resulting tensile stress may lead to distortion, cracking, and delamination, which is a major problem for industrial processing. ${ }^{7,8}$ The introduction of an inorganic nonshrinking phase into the polymer matrix has been used to reduce overall shrinkage, e.g., shrinkage reduction from $7 \%$ to $2.5 \%$ was achieved with the addition of $57 \%$ glass filler. ${ }^{9}$ The composite approach is attractive because it also improves the mechanical properties in terms of hardness, stiffness, scratch resistance,

Correspondence to: Y. Leterrier (yves.leterrier@epfl.ch).

Contract grant sponsor: Swiss National Science Foundation; contract grant number: SNF project 200020111706.

Journal of Applied Polymer Science, Vol. 114, 1954-1963 (2009) (c) 2009 Wiley Periodicals, Inc. and coefficient of thermal expansion. ${ }^{10-14}$ However, an increase in stiffness of the material usually has a disadvantageous effect on the internal stress, as has been shown by Condon and Ferracane ${ }^{15}$ for highly filled dental composites.

Shrinkage is the result of double-bond conversion. Therefore, kinetic studies were performed to determine the influence of a filler on the polymerization behavior of a resin and on the level of conversion. ${ }^{16-19}$ Harsch et al. ${ }^{20}$ found a reduction in conversion of epoxy resin when silica filler was added. In contrast, Cho et al. ${ }^{19}$ showed that formulations containing silica nanoparticles gave higher ultimate conversion. The latter result would most likely favor shrinkage and stress. ${ }^{21}$

Some studies demonstrated that higher intensities lead to higher conversion, ${ }^{22,23}$ whereas others showed that conversion was only a question of energy input. ${ }^{24}$ Because shrinkage is closely related to conversion, UV intensity also plays a role in the dynamics of shrinkage. Polymerization contraction was found to increase with intensity, ${ }^{25,26}$ but exothermic temperature rise can expand the volume and reduce the shrinkage at high intensities. ${ }^{27}$

A further approach toward shrinkage reduction is the use of hyperbranched polymers (HBP), which belong to the group of macromolecules known as dendritic polymers. ${ }^{28-31}$ Acrylated HBP were demonstrated to have significantly lower shrinkage and internal stresses than standard acrylates. ${ }^{21}$ These features proved to be the key to producing a variety of 


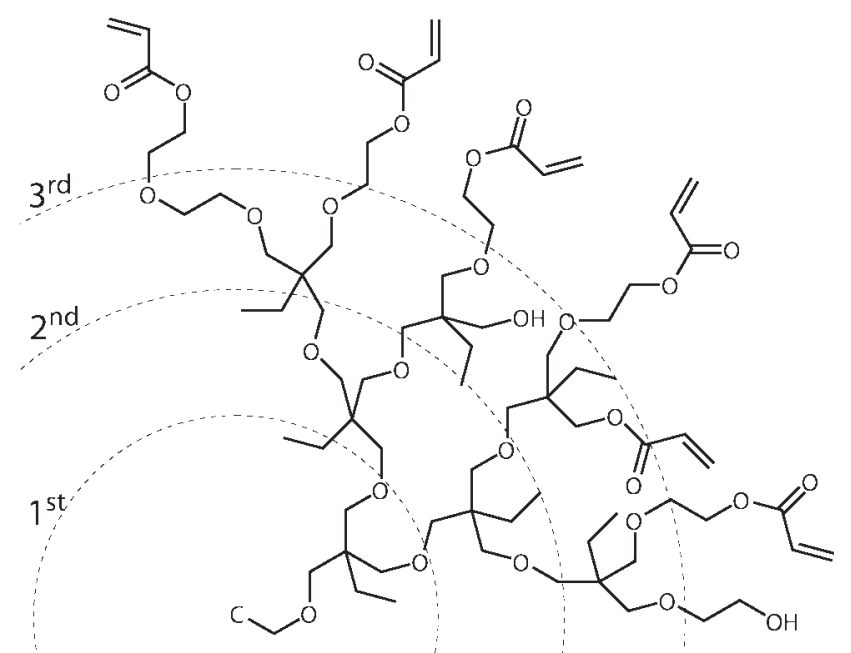

Figure 1 Structure of the acrylated hyperbranched polymer. The three ring segments represent the three generations. $\mathrm{C}$ denotes the core of the molecule from where four branches grow out. Only one sample branch is shown.

microstructures with high dimensional accuracy. ${ }^{32,33}$ This is because HBP has a very high acrylate equivalent weight, yielding in a highly crosslinked material by forming only a few intermolecular bonds. Moreover, as a result of their globular structure HBP and dendrimers exhibit Newtonian behavior ${ }^{34}$ that should be useful in postponing the liquid-to-solid transition, which compromises nanocomposite processing, to high nanoparticle loadings. The benefits of UV-curable HBPs for fast conversion were highlighted in recent investigations, although these were limited to unfilled systems. ${ }^{21,35}$

The goal of this work was to investigate the conversion of UV-curable hyperbranched polymer nanocomposites, and resulting shrinkage paying particular attention to the influence of nanofiller and UV light.

\section{MATERIALS AND METHODS}

\section{Materials}

The monomer was based on a third-generation hyperbranched polyether polyol, giving a 29-functional hyperbranched polyether acrylate (Perstorp $A B$, Sweden); its structure is depicted in Figure 1. The HBP was derived from the ring-opening polymerization of 3-ethyl-3-(hydroxymethyl)oxetane ${ }^{36}$ and was terminated with ethylene oxide to increase flexibility and reduce the viscosity. Table I gives an overview of the physical properties of the acrylated HBP.

The photo-initiator was 1-hydroxy-cyclohexyl-phenyl-ketone (Irgacure ${ }^{\circledR} 184$, Ciba Specialty Chemicals) at a concentration equal to $1 \mathrm{wt} \%$. It showed good solubility in the acrylate monomer.
Two nanofillers were studied, both made of amorphous silica. Highlink ${ }^{\circledR}$ NanO G502 (Clariant) is a suspension of $30 \mathrm{wt} \%$ monodispersed $\mathrm{SiO}_{2}$ in isopropanol. The average particle size according to the supplier is $13 \mathrm{~nm}$, which corresponds to a specific surface area of about $230 \mathrm{~m}^{2} / \mathrm{g}$. X-ray disc centrifuge (BI-XDC, Brookhaven) measurements gave an average particle size of $23 \mathrm{~nm}$ with a standard deviation

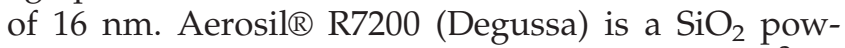
der with a specific surface area of about $150 \mathrm{~m}^{2} / \mathrm{g}$. The primary particle size is $12 \mathrm{~nm}$, but agglomerates up to several micrometers were observed. Aerosil particles were subjected to surface treatment with methacrylsilane to promote interphase properties.

\section{Sample preparation}

First, the photo-initiator was dissolved in the HBP while stirring at $70^{\circ} \mathrm{C}$ for $30 \mathrm{~min}$. Compositions with 5 and $20 \mathrm{vol} \% \mathrm{SiO}_{2}$ were then prepared. The corresponding amount of Highlink was mixed with the HBP and stirred for one hour. Aerosil was dispersed in isopropanol (ratio $1: 3$ by weight) and processed with ultrasound (Digital Sonifier 450, Branson) to desagglomerate the aggregates. A corresponding amount of the suspension was then mixed with the HBP for $1 \mathrm{~h}$. The solvent was evaporated at $40^{\circ} \mathrm{C}$ under vacuum. Electron micrographs of the composite with $5 \mathrm{vol} \% \mathrm{SiO}_{2}$ are shown in Figure 2. The micrograph samples were embedded in epoxy resin after polymerization and cut into 40-nm-thick slices

TABLE I

Physical Properties of the Acrylated Hyperbranched Polymer and Its Composites

\begin{tabular}{llc}
\hline \multicolumn{1}{c}{ Property } & \multicolumn{1}{c}{ Unit } & Value \\
\hline Theoretical functionality & & 32 \\
Actual functionality & & 29 \\
$M_{w}$ & $\mathrm{~g} / \mathrm{mol}$ & 7976 \\
$M_{n}$ & $\mathrm{~g} / \mathrm{mol}$ & $\sim 3000$ \\
Acrylate equivalent weight & $\mathrm{g}_{\text {Resin }} / \mathrm{mol}_{\mathrm{AG}}$ & 275 \\
$\begin{array}{l}\text { Degree of branching } \\
\quad \text { (Frechet et al. }{ }^{31} \text { ) }\end{array}$ & & 0.41 \\
$\mathrm{~T}_{\mathrm{g}}$ monomer & ${ }^{\circ} \mathrm{C}$ & -54 \\
$\mathrm{~T}_{\mathrm{g}}$ polymer & ${ }^{\circ} \mathrm{C}$ & 9 \\
$\mathrm{~T}_{\mathrm{g}}$ all composites & ${ }^{\circ} \mathrm{C}$ & 9 \\
Newtonian viscosity & $\mathrm{Pa}^{*} \mathrm{~s}$ & 4.6 \\
$\quad$ of HBP $\left(20^{\circ} \mathrm{C}\right)$ & & $7.3 / 50$ \\
Viscosity of Aerosil composite & $\mathrm{Pa}^{*} \mathrm{~s}$ & \\
$\quad(5 / 20$ vol $\%)$ at $1 \mathrm{~Hz}$ & & $60 / 900,000$ \\
Viscosity of Highlink composite & $\mathrm{Pa}^{*} \mathrm{~s}$ & \\
$\quad(5 / 20$ vol $\%$ ) at $1 \mathrm{~Hz}$ & &
\end{tabular}

$M_{w}$, mass molecular weight (calculated from the hydroxyl number); $M_{n}$, number molecular weight (taken from the specifications of the supplier); AG, acrylate group. The number of acrylate functionalities per monomer were taken from the specifications of the supplier. The degree of branching was taken from the work of Magnusson et al. ${ }^{35}$ on hyperbranched aliphatic polyether. 

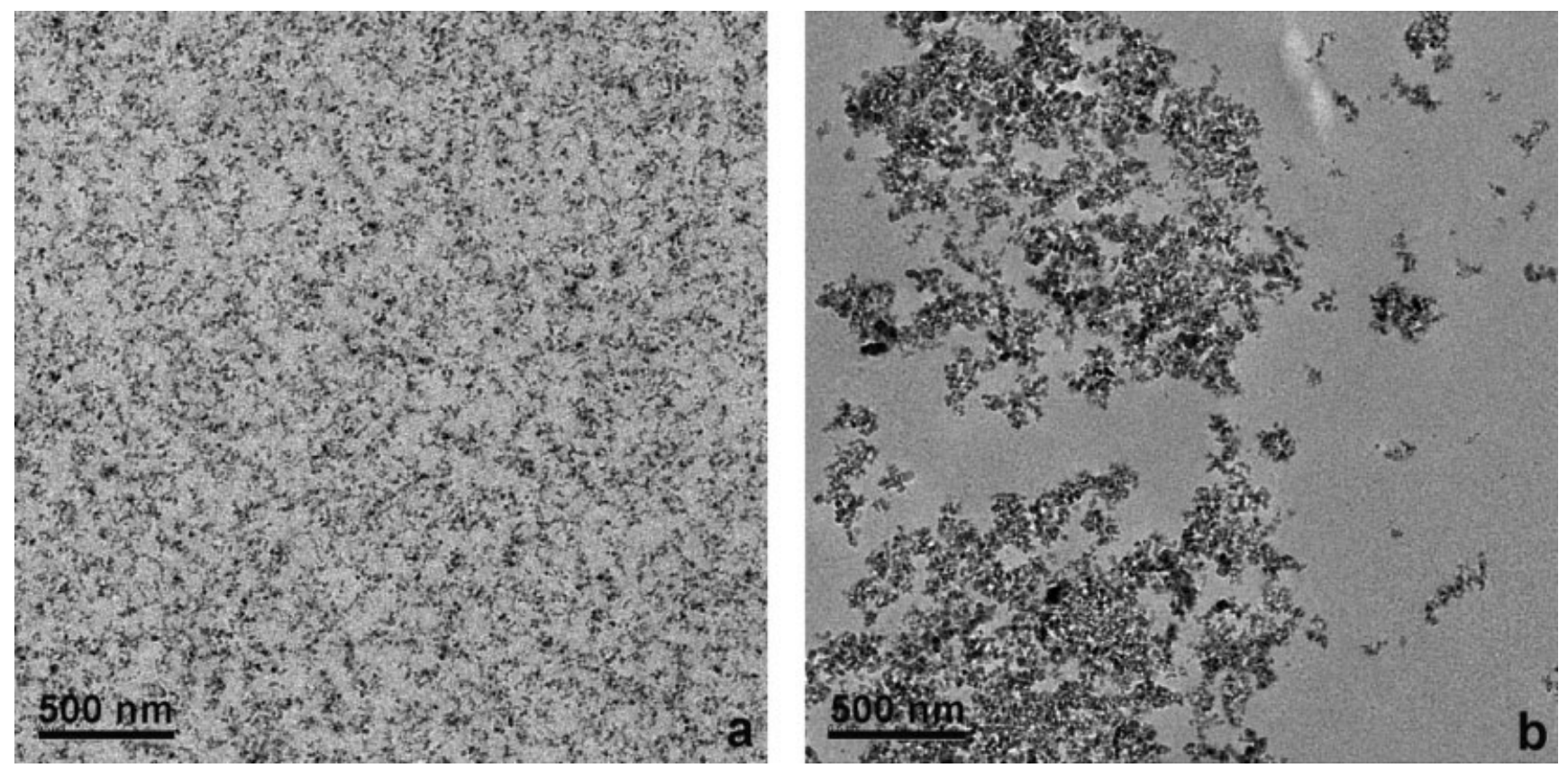

Figure 2 Transmission electron micrographs of HBP composites containing 5 vol\% of (a) Highlink and (b) Aerosil.

using a microtome (Ultracut E, FC 4D, ReichertJung) with a diamond knife. Observations were made at $200 \mathrm{kV}$ in a transmission electron microscope (TEM, Philips/FEI, CM20). The composites containing Highlink were true nanocomposites, where the inorganic phase was monodispersed in the polymer matrix. In contrast, the Aerosil powder could not be completely desagglomerated after the ultrasound treatment, resulting in micrometer size aggregates. The dispersion state had a strong influence on the rheological behavior of the composites, i.e., better dispersion led to higher viscosities (Table I).

\section{METHODS}

\section{UV lamp and spectrometer}

A UV lamp with a 200-W mercury bulb (OmniCure 2000, Exfo, Canada) was used for all experiments. The light intensity was measured using a spectrometer (Sola-Check 2000, Solatell, United Kingdom) over a range of $270-470 \mathrm{~nm}$.

\section{UV-vis absorption}

Absorption measurements were carried out on a UV/VIS/NIR spectrometer (Lambda 19, Perkin Elmer) at $1 \mathrm{~nm} / \mathrm{s}$.

\section{Rheology}

Viscosity measurements were carried out on a strain-controlled rotational rheometer (ARES, Rheo- metric Scientific, 2kFRT transducer) at $1 \mathrm{~Hz}$ and at room temperature using cone-plate geometry with a diameter of $25 \mathrm{~mm}$.

\section{Differential scanning calorimetry (DSC)}

The glass transition temperature $\left(T_{g}\right)$ of the HBP and the nanocomposites was measured by means of differential scanning calorimetry (DSC, Q100, TA Instruments) at a heating rate of $10 \mathrm{~K} / \mathrm{min}$ as the middle point of the transition.

\section{Photo DSC}

The heat of the photo-polymerization reaction was measured by means of photo DSC (Q100, TA Instruments). The apparatus was provided with a photocalorimetric accessory. The cell was sealed with a quartz window that let the UV light pass onto the open aluminum sample pans. Measurements were carried out at room temperature. The residual temperature increase of the sample, due to the irradiation of the lamp, was less than $1^{\circ} \mathrm{C}$. The sample space was flushed with nitrogen. To ensure equal illumination conditions throughout the sample volume, the samples were weighed to give a thickness of $500 \mu \mathrm{m}$. At the selected photo-initiator concentration of $1 \mathrm{wt} \% .38 \%$ of UV light was absorbed throughout the sample thickness. ${ }^{1}$ The measurements were carried out at intensities ranging from 0.5 to $50 \mathrm{~mW} / \mathrm{cm}^{2}$, and the conversion was calculated according to Hoyle and Pappas ${ }^{37}$ by integration of the area under the exothermic peak. The total heat (Joule/gram) was normalized according to the 

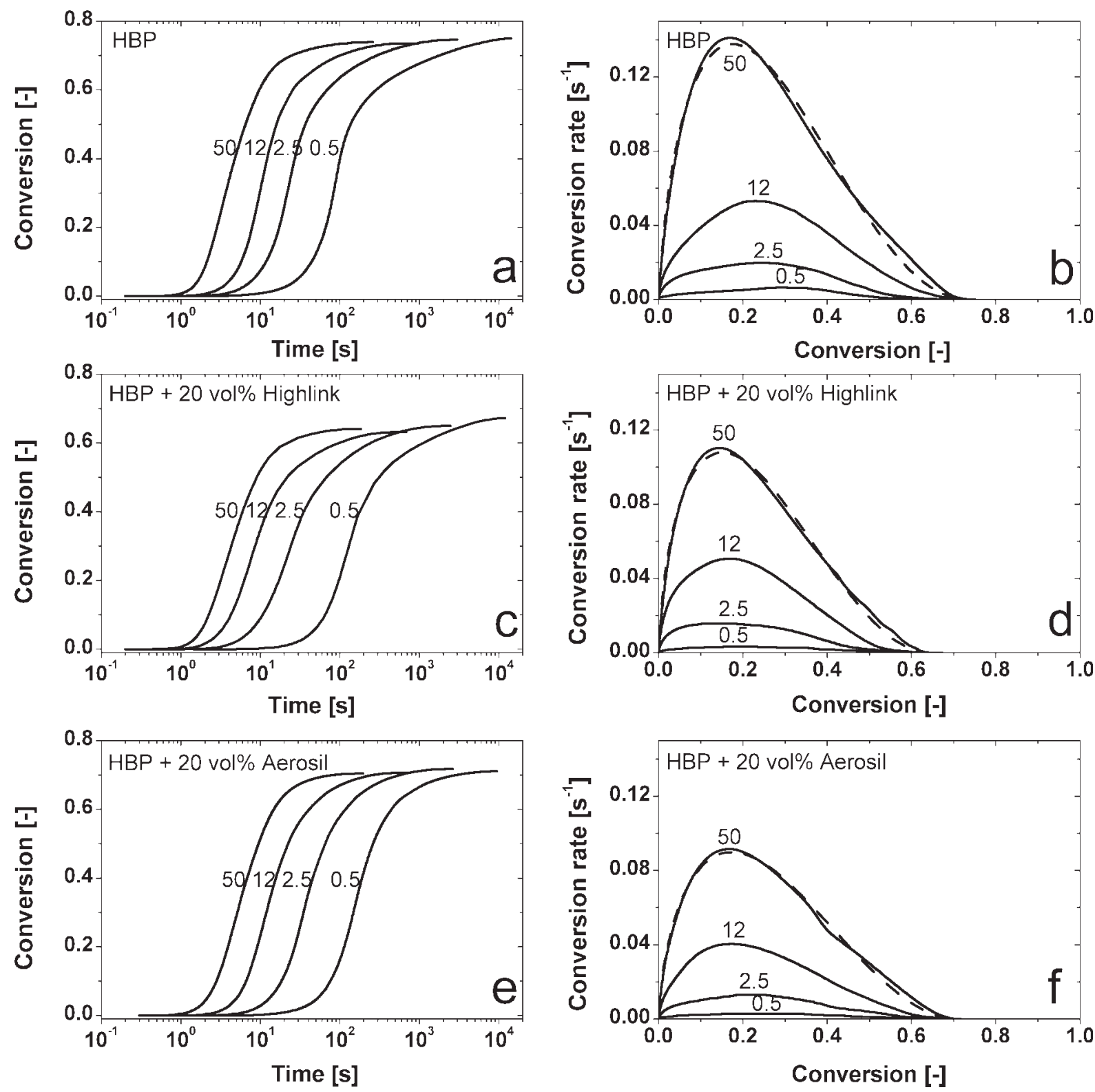

Figure 3 ( $a, c$, and e) Conversion as a function of time, and (b, d, and f) conversion rate as a function of conversion at different intensities [milliwatt per square centimeter] for HBP and Highlink and Aerosil composites. The autocatalytic model is compared with the conversion rate data for an intensity of $50 \mathrm{~mW} / \mathrm{cm}^{2}$ (dashed line).

amount of resin in the composite. The theoretical heat attained per acrylate double bond was $\Delta H_{\text {theor }}$ $=86.41 \mathrm{~kJ} / \mathrm{mol}^{38}$

\section{Interferometry}

Polymerization shrinkage was measured with a Michelson interferometer that is described in detail in the work of de Boer et al. ${ }^{39}$ and Schmidt. ${ }^{40}$ A 100$\mu \mathrm{m}$-thick layer of sample, spread on a glass substrate using a doctor blade, was mounted in a sealed chamber flushed with nitrogen. The sample was exposed to UV light and the resulting thickness contraction was monitored by means of laser interfer- ometry. The thickness of the sample after UV illumination, from which the initial thickness and total shrinkage could be back-calculated, was determined with a profilometer. The refractive index, which was needed for the calculations, was measured using a standard refractometer. The accuracy of the shrinkage measurement was $\sim 10 \%$.

\section{RESULTS AND DISCUSSION}

\section{Photocalorimetry analysis}

Figure 3 shows the double bond conversion as a function of time and UV intensity for HBP and composites containing Highlink and Aerosil. After the 


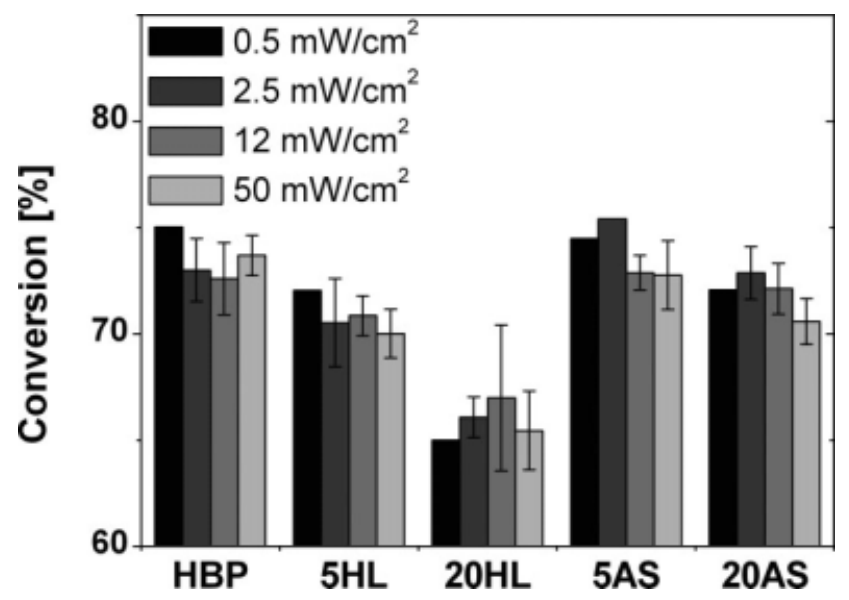

Figure 4 Ultimate conversion for HBP and composites containing 5 and $20 \mathrm{vol} \%$ Highlink (HL) and Aerosil (AS) polymerized at different intensities.

reaction took off, the conversion increased rapidly and then slowed down again, until a plateau value was reached. The induction time depended on the UV intensity and was attributed to the formation of initiator-derived radicals and the inhibiting effect of dissolved oxygen. The final conversion of the HBP was $73 \%$, which was reduced to $65 \%$ and $72 \%$ for the composites with $20 \mathrm{vol} \%$ Highlink and Aerosil, respectively.

It is evident that the intensity did not influence the maximum conversion of the HBP or the composites. This result is contrary to the results reported by Schmidt et al. ${ }^{22}$ and Lecamp et al., ${ }^{23}$ who found that conversion increased at higher intensities. This difference resulted from the choice of limits for the integration of the heat flow with time. In the present case, the DSC peak was integrated from the time the lamp was switched on until the time when there was no longer any measurable change in the heat flow by DSC. Schmidt defined the conversion reaction to be completed when the heat flow reached 1/100th of its maximum value. ${ }^{41}$ By choosing the same integration criteria as Schmidt, the influence of the intensity on the maximum conversion also became apparent.

In all cases, two main polymerization stages were identified. These were already observed for other acrylate systems, including $\mathrm{HBP},{ }^{22}$ and for silica nanocomposites. ${ }^{19}$ At the beginning of the reaction, a sharp increase in the rate of polymerization was evident, which corresponded to gelation or autoacceleration. Due to the increasing viscosity, the mobility of the long-chain radical species was reduced; hence, two radical species were less likely to approach each other and recombine. Consequently, the rate constant for termination dropped, and the rate of polymerization increased. Initiation and propagation were barely affected by the increased viscosity of the reactive mixture, because the mobility of the small monomers was still high. During the second stage, which started after going through a maximum rate of polymerization, the reaction rate dropped quicker than would be expected due to the consumption of monomers only (autodeceleration). The overall reaction then became purely diffusion controlled. Because the cure temperature was above the ultimate $T_{g}$ of the cured materials, a third stage, controlled by vitrification, could not be identified in any of the mixtures. ${ }^{22}$

Figure 4 depicts the ultimate conversion for all materials investigated. It is evident that the final conversion in Highlink composites decreased with the filler volume fraction $\Phi(11 \%$ reduction at $\Phi=$ $20 \mathrm{vol} \%)$ compared to HBP, whereas the final conversion of the Aerosil composites was nearly independent of $\Phi(1.5 \%$ reduction at $\Phi=20 \mathrm{vol} \%)$. The observed reduction of the total conversion on addition of a filler was also found by Harsch et al. ${ }^{20}$ for composites based on epoxy resin and $\mathrm{SiO}_{2}$ particles. On the contrary, Cho et al. ${ }^{19}$ showed that formulations containing silica nanoparticles give higher exothermic peak and ultimate conversion, as well as shorter induction time. They suggested that silica particles behaved as an effective flow or diffusionaid agent for the photo-polymerization process. However, this phenomenon is unlikely, because the viscosity of the composite increases with filler loading, thus reducing the mobility of the reacting species. UV absorption measurements showed slightly improved transparency for the Highlink composites than for HBP in the range of 250-500 nm (Fig. 5). Therefore, light scattering due to nanoparticles can be excluded as a source of decreased conversion. The increased transparency of the Highlink composites was due to their reduced refractive index compared with that of the HBP, hence increased Fresnel transmittance coefficient $T$ according to ${ }^{42}$

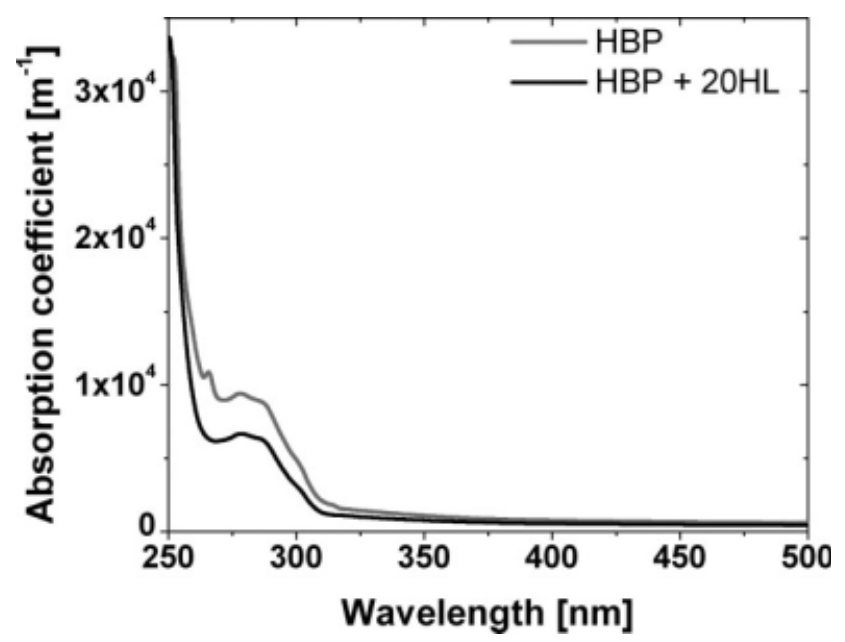

Figure 5 UV absorption of cured HBP and of a composite containing $20 \mathrm{vol} \%$ of Highlink. 


$$
T=\frac{4 n_{m}}{\left(n_{m}+1\right)^{2}+\kappa_{m}^{2}}
$$

where $n_{m}$ and $\kappa_{m}$ are the refractive and extinction indices of the material, respectively. The refractive index of the composite is a function of the refractive indices of the HBP $\left(n_{m}=1.49-1.5\right.$ measured with a standard refractometer) and $\mathrm{SiO}_{2}\left(n_{m}=1.46\right.$ at 500 $\mathrm{nm}^{43}$ ) and often behaves linearly with the volume fraction. ${ }^{43,44}$ The refractive index of the composite containing $20 \mathrm{vol} \%$ of Highlink was found to be equal to 1.481 . The extinction index is negligible for the considered materials in the visible range. The transmittance of the nanocomposite at $500 \mathrm{~nm}$ is equal to $96.24 \%$ according to eq. (1), which is higher than that of the HBP, found to be in the range 96.0-96.1\%.

The data obey a time-intensity superposition, which is further explained in a separate study. A power-law relation between intensity and the timeintensity shift factor, with an exponent equal to 0.71 was found.

\section{Conversion modeling}

One phenomenological model successfully applied to UV-curing of acrylates and acrylate composites is the autocatalytic model ${ }^{45-47}$ :

$$
\frac{d \alpha}{d t}=k \alpha_{r}^{m}\left(1-\alpha_{r}\right)^{n}
$$

where $\alpha_{r}=\alpha / \alpha_{\max }$ is the relative conversion, normalized with respect to the maximum conversion $\alpha_{\text {max }}, t$ is the time, $n$ is the reaction order, and $m$ is the autocatalytic exponent that stands for the autoacceleration of the UV reaction, i.e., the immobilization of the reactive chain ends, due to an increase in viscosity, resulting in a drop in the termination rate. This model was derived from the autocatalytic Kamal model, ${ }^{48}$ which was developed for the thermal cure of polyesters. The shape of the photo-initiated polymerization rate curves was the same as for the autocatalytic reaction. Although photo-initiated polymerization is autoaccelerated and not autocatalyzed, this model was applied to describe these reactions in a purely phenomenological way. Some fits are shown in Figure 3. The rate constant $k$ was modeled assuming power law dependence of UV intensity:

$$
k=k_{0}(\phi) \cdot I^{\beta}
$$

where $k_{0}$ is a factor that depends on the filler fraction $\varphi$, and $I$ is the UV intensity. The exponent $\beta$ is related to the termination mechanism. For $\beta<0.5$, primary radical termination is predominant, i.e., reaction of an initiator radical with a radical site on the evolving polymer. For $\beta=0.5$, second order is predominant, i.e., the reaction of two radical polymer sites. For $0.5<\beta<1$, first order termination, i.e., trapping of the radical end in the forming network or recombination with oxygen, and secondorder termination happen in parallel. For $\beta=1$, first-order termination is predominant. ${ }^{49}$

\section{Influence of intensity}

The rate constant of the HBP and the composites strongly depended on intensity [Fig. 6(a)]. The

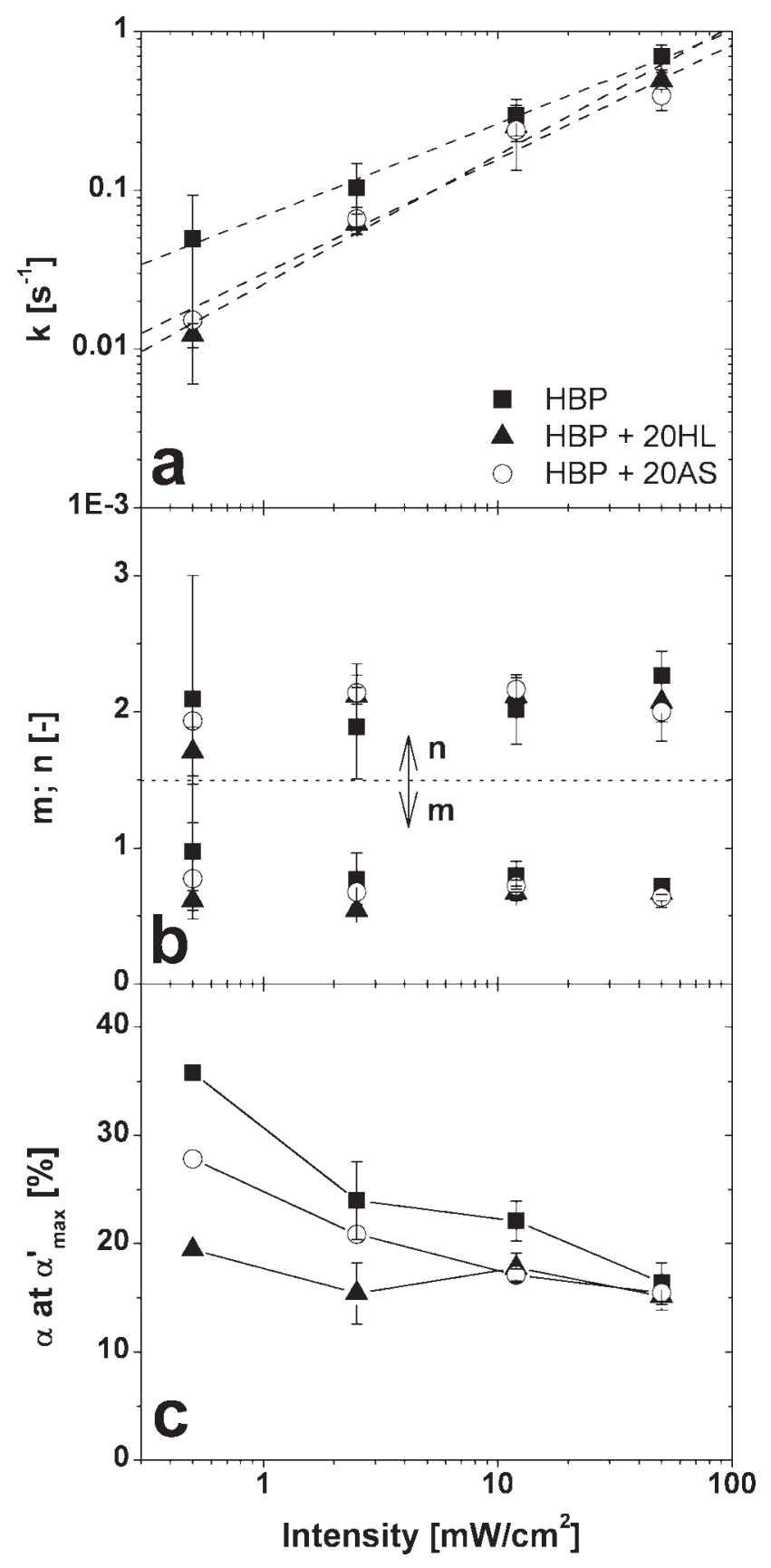

Figure 6 (a) Rate constant $k$, (b) reaction order $m$ and autocatalytic exponent $n$, and (c) conversion at maximum conversion rate as a function of intensity for HBP and composites containing $20 \mathrm{vol} \%$ of Highlink (HL) and Aerosil (AS). 


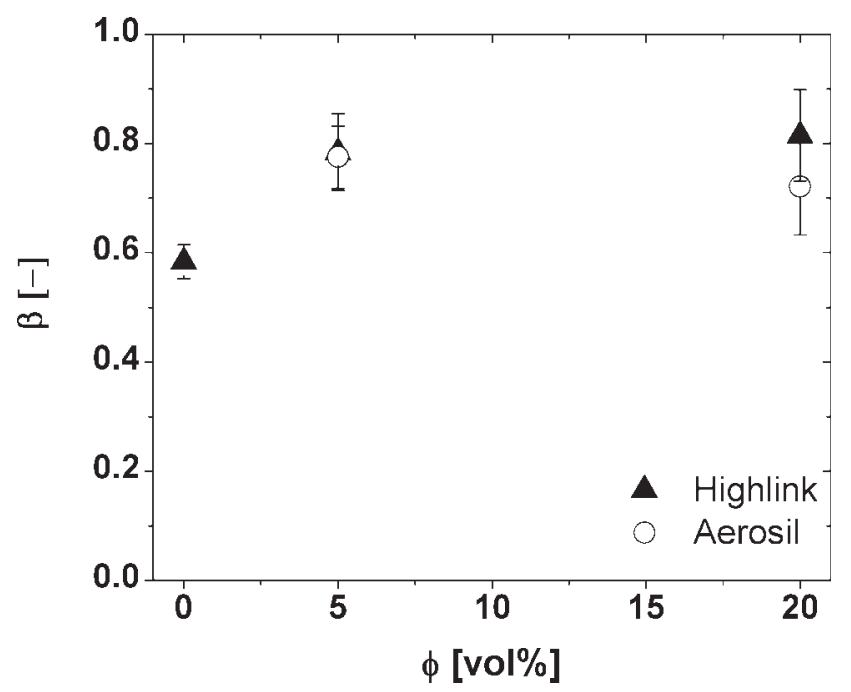

Figure 7 Intensity exponent $\beta$ for Highlink and Aerosil composites at different filler fractions.

intensity exponent $\beta$ (Fig. 7) was found to be in the range of $0.6-0.8$, which matches the previously mentioned intensity exponent for the time-intensity superposition. As $\beta$ was between 0.5 and 1 for all composites, this result indicates that first-order and second-order termination mechanisms occurred simultaneously. In contrast, the work of Schmidt et al. ${ }^{22}$ and Timpe et al. ${ }^{50}$ gave values for $\beta$ smaller than 0.5 , indicating that primary radical termination was predominant. The degree of branching (DB) of the acrylated HBP used by the former authors was equal to 0.35 , which is lower than that in the present work (0.41). A lower DB implies that additional reactive sites are less accessible and in fact are available for radicals trapping, leading to $\beta$ smaller than 0.5. First-order termination includes the reaction of radicals with oxygen. Higher amounts of dissolved oxygen could have been the reason for the higher $\beta$ values in the present case. The addition of a filler or precursor increased $\beta$, but did not change the termination mechanism.

The reaction order, $m$, and the autocatalytic exponent, $n$, were independent of intensity [Fig. 6(b)]. The reaction order was around 0.7 and the autocatalytic exponent around 2, so that the overall reaction order was $\sim 2.7$. This is close to the reaction order 3 that was found in a previous study on dimethacrylate oligomers. ${ }^{51}$

The conversion at maximum conversion rate, $\alpha_{\text {max }}^{\prime}$ increased toward lower intensities, as seen in Figure 6(c). An increase in conversion at $\alpha_{\max }^{\prime}$ is comparable with a shift of gelation to a higher conversion. Microgelation ${ }^{52,53}$ is the formation of macromolecules that are no longer soluble in the unreacted monomer liquid. At this stage, conversion proceeds in a macroscopic liquid state in which shrinkage stress does not build up. Low intensities seemed to favor the formation of microgels and therefore increased the conversion at $\alpha_{\text {max }}^{\prime}$. The same result was found by Neves et al. ${ }^{24}$ for the photo-polymerization of acrylate composites. In this case and in the present case lower viscosities were maintained during longer times when lower intensities were used, which favored increased conversion before macroscopic gelation. Anseth et al $^{38}$ found the opposite trend and explained this with delayed volume shrinkage at higher intensities that subsequently led to higher final conversion. This was not observed in the present work, where the final conversion was independent of UV intensity (Fig. 4). A shift of gelation toward higher conversion allows the material to relax more shrinkage stress which is favorable for the production of low-stress materials.

\section{Influence of composition and nanostructure}

The rate constant marginally decreased with filler fraction [Fig. 8(a)], in contrast with the large influence of UV intensity shown in Figure 6(a). The mobility of the reacting species is, therefore, only weakly influenced by the considerable increase in viscosity of the nanocomposite mixture reported in Table I. The reaction order $m$ and the autocatalytic constant $n$ were independent of the filler fraction for all composites [Fig. 8(b)]. Because $n$ and $m$ were also independent of intensity within experimental scatter, the conversion state of all materials investigated is fully described by the change of one single intensity and filler loading dependent rate constant. Composites showed reduced conversion at $\alpha_{\text {max }}^{\prime}$ compared with HBP [Fig. 8(c)], particularly at low intensities. As pointed out earlier, the conversion at $\alpha_{\text {max }}^{\prime}$ is related to gelation of the material. The increased viscosity of the composites due to the nanofiller reduced the mobility of the reacting species, leading to early gelation of the surrounding polymer and eventually reducing final conversion. This effect was more pronounced for Highlink composites owing to their considerably higher viscosity resulting from the improved dispersion state of the nanoparticles compared with Aerosil composites. Interestingly, the dispersion state of the nanocomposites did not significantly influence the rate constant or the overall reaction order. However, better dispersion led to earlier gelation, especially at low intensities, and lower ultimate conversion, with probable consequences in terms of stress buildup. ${ }^{21}$

\section{Influence of composition and intensity on shrinkage}

As shown in Figure 9, the addition of a filler reduced the overall shrinkage of the composite. The same trend was found by Atai and Watts ${ }^{9}$ for acrylate composites containing a glass filler. The 


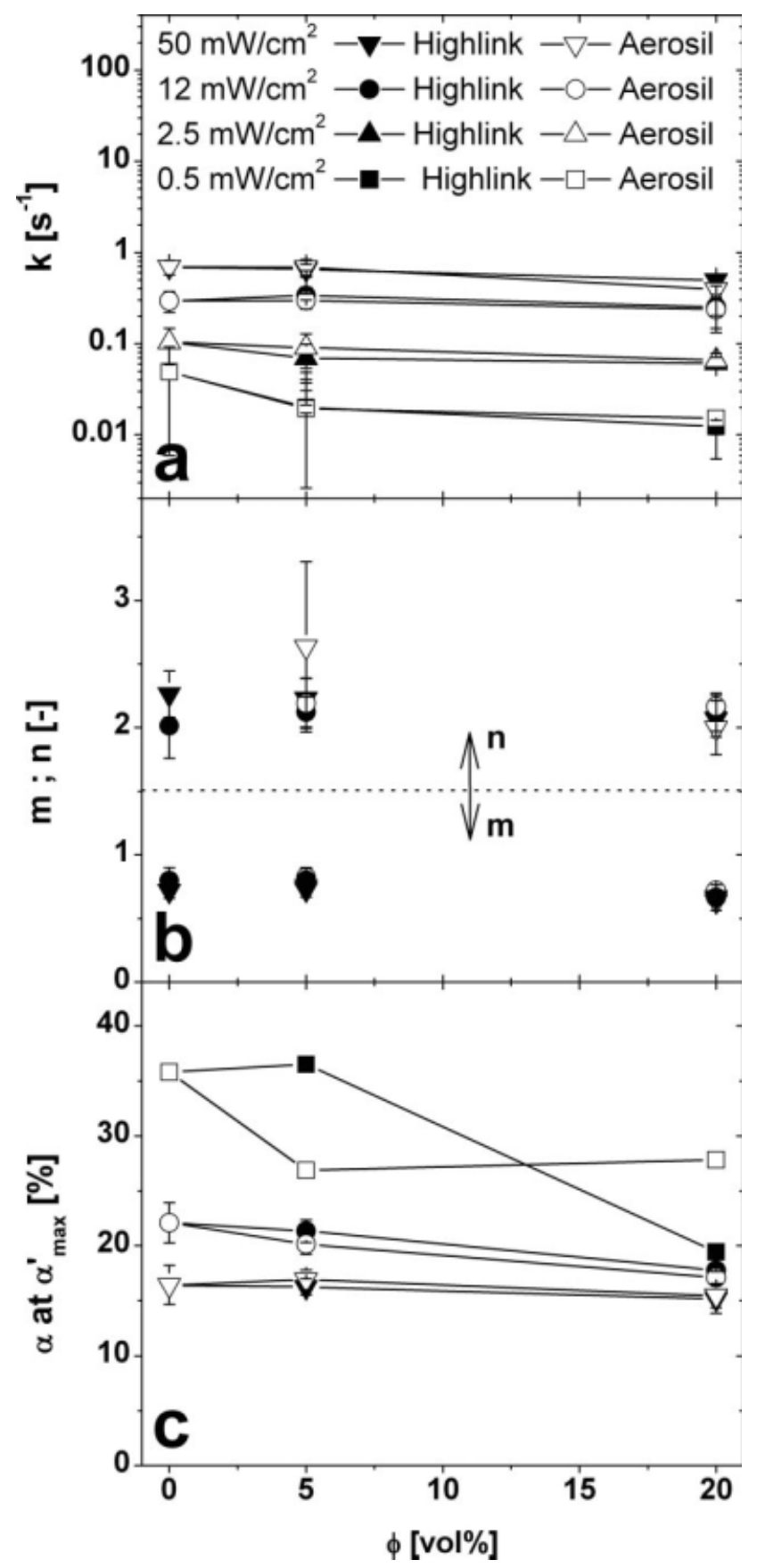

Figure 8 (a) Rate constant $k$, (b) reaction order $m$ and autocatalytic exponent $n$, and (c) conversion at maximum conversion rate as a function of filler fraction and intensity for Highlink and Aerosil composites.

shrinkage of the composite containing $20 \mathrm{vol} \%$ Highlink was reduced by $26 \pm 14 \%$ compared with the pure HBP. Therefore, the rule of mixture was obeyed within experimental scatter:

$$
S_{\text {comp }}=S_{\mathrm{HBP}}(1-\phi)
$$

where $S_{\text {comp }}$ and $S_{\mathrm{HBP}}$ are the linear shrinkage of the composite and the HBP, respectively, and $\varphi$ is the filler volume fraction.
Despite a rather high experimental scatter, it was observed that at $50 \mathrm{~mW} / \mathrm{cm}^{2}$ Aerosil composites with higher final conversion shrank more than Highlink composites with lower final conversion, which confirmed that shrinkage is in fact related to conversion. $.7,54,55$ Assuming that conversion and shrinkage are linearly related, which was observed for nonvitrifying systems, ${ }^{39}$ one writes:

$$
S_{\text {comp }}=S_{\mathrm{HBP}} \frac{\alpha_{\text {comp }}}{\alpha_{\mathrm{HBP}}}(1-\phi)
$$

where $\alpha_{\text {comp }}$ and $\alpha_{\mathrm{HBP}}$ are the conversion of the composite and the HBP, respectively. The experimental scatter did not enable us to evaluate the validity of the models.

The reduction of shrinkage observed at the higher intensity resulted from an exothermic effect, as already investigated by Stansbury et al. ${ }^{27}$. In the present case, a temperature rise of $7^{\circ} \mathrm{C}$ at $12 \mathrm{~mW} / \mathrm{cm}^{2}$ and $14^{\circ} \mathrm{C}$ at $50 \mathrm{~mW} / \mathrm{cm}^{2}$ was recorded during the photo-polymerization reaction. The increased temperature at high intensities enabled network formation to take place in a more expanded state.

With $20 \mathrm{vol} \%$ filler loading combined with an intensity increase from 12 to $50 \mathrm{~mW} / \mathrm{cm}^{2}$, an overall shrinkage reduction of $33 \%$ down to $3 \%$ linear shrinkage was achieved. This corresponds to $\sim 9 \%$ volumetric shrinkage, which is very low in comparison with $42 \%$ volumetric shrinkage ${ }^{56}$ for the standard photo-resist SU8 and $10-26 \%$ for various methacrylate esters. ${ }^{54}$ This is a promising result for the reduction of internal stress during photo-polymerization, and for an improvement of the dimensional accuracy of polymer micro- and nanostructures, such as those produced using nanoimprint lithography. ${ }^{57}$

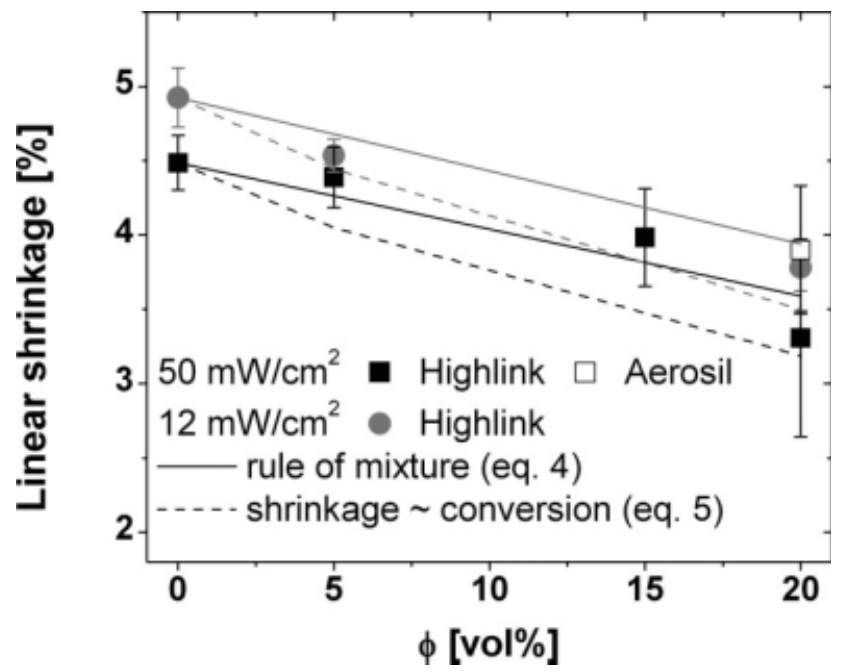

Figure 9 Linear shrinkage of composites as a function of filler fraction at different intensities. Equations (4) and (5) are compared with the experimental data. 


\section{CONCLUSIONS}

The influence of UV intensity and of nanosized $\mathrm{SiO}_{2}$ particles on the photo-polymerization and shrinkage behavior of an acrylated HBP was investigated. Time-intensity superposition was applied to reduce the conversion curves onto one master curve. The shift factor showed power-law dependence on the intensity with an exponent equal to 0.71 . An autocatalytic model was used to analyze the experimental conversion data. The reaction order and the autocatalytic exponent were found to be independent of the filler fraction and the intensity. The overall reaction order was $\sim 2.7$. The reaction rate was found to have power-law dependence on the UV intensity with an exponent equal to 0.6 for the HBP, and in the $0.7-0.8$ range for the composites, thereby suggesting that the main termination mechanisms were a combination of first and second orders. Low intensities were able to prolong the existence of microgels, during which conversion proceeds in a macroscopic liquid state, and shrinkage stress does not buildup. This delay in macroscopic gelation presents advantages for the production of low-stress materials.

The ultimate conversion was found to be lower for the composites compared with the pure HBP. This effect was emphasized in the case of good dispersion of the silica particles, attributable to early gelation of the system as a result of increased viscosity and therefore reduced mobility of the reacting species. This, combined with the use of high UV intensities, enabled the overall shrinkage to be reduced to $3 \%$, which should facilitate the production of low-stress polymer nanostructures with high dimensional accuracy.

The authors thank Henrik Bernquist from Perstorp AB for useful advice and the supply of samples.

\section{References}

1. Schmidt, L. E.; Leterrier, Y.; Vesin, J. M.; Wilhelm, M.; Månson, J.-A. E. Macromol Mater Eng 2005, 290, 1115.

2. Luciani, A.; Plummer, C. J. G.; Gensler, R.; Månson, J.-A. E. J Coat Technol 2000, 72, 161.

3. Fouassier, J. P.; Rabek, J. F. Radiation Curing in Polymer Science and Technology; Elsevier Science Publishers Ltd: NewYork, 1993.

4. Chen, M. H.; Chen, C. R.; Hsu, S. H.; Sun, S. P.; Su, W. F. Dent Mater 2006, 22, 138.

5. Dewaele, M.; Truffier-Boutry, D.; Devaux, J.; Leloup, G. Dent Mater 2006, 22, 359.

6. Pappas, S. P. Radiation Curing; Plenum Press: New York, 1992.

7. Jakubiak, J.; Linden, L. A. Polimery 2001, 46, 522.

8. Lu, L.; Fuh, J. Y. H.; Nee, A. Y. C.; Kang, E. T.; Miyazawa, T.; Cheah, C. M. Mater Res Bull 1995, 30, 1561.

9. Atai, M.; Watts, D. C. Dent Mater 2006, 22, 785.
10. Plummer, C. J. G.; Garamszegi, L.; Leterrier, Y.; Rodlert, M.; Månson, J.-A. E. Chem Mater 2002, 14, 486.

11. Hussain, F.; Hojjati, M.; Okamoto, M.; Gorga, R. E. J Compos Mater 2006, 40, 1511.

12. Condon, J. R.; Ferracane, J. L. J Dent Res 1997, 76, 1405.

13. Sham, M. L.; Kim, J. K. Compos A 2004, 35, 537.

14. Rodlert, M.; Plummer, C. J. G.; Garamszegi, L.; Leterrier, Y.; Grunbauer, H. J. M.; Månson, J.-A. E. Polymer 2004, 45, 949.

15. Condon, J. R.; Ferracane, J. L. J Am Dent Assoc 2000, 131, 497.

16. Tomecek, P.; Horakova, V.; Lapcik, L. J Polym Mater 2003, 20, 399.

17. Roman, F.; Montserrat, S.; Hutchinson, J. M. J Therm Anal Calorim 2007, 87, 113.

18. Lu, M. G.; Shim, M.; Kim, S. Polym Eng Sci 1999, 39, 274.

19. Cho, J. D.; Ju, H. T.; Hong, J. W. J Polym Sci Part A Polym Chem 2005, 43, 658.

20. Harsch, M.; Karger-Kocsis, J.; Holst, M. Eur Polym J 2007, 43, 1168.

21. Schmidt, L. E.; Schmah, D.; Leterrier, Y.; Månson, J.-A. E. Rheol Acta 2007, 46, 693.

22. Schmidt, L. E.; Leterrier, Y.; Schmah, D.; Månson, J.-A. E.; James, D.; Gustavsson, E.; Svensson, L. S. J Appl Polym Sci 2007, 104, 2366.

23. Lecamp, L.; Youssef, B.; Bunel, C.; Lebaudy, P. Polymer 1997, 38,6089

24. Neves, A. D.; Discacciati, J. A. C.; Orefice, R. L.; Yoshida, M. I. J Biomed Mater Res Part A Appl Biomater 2005, 72, 393.

25. Asmussen, E.; Peutzfeldt, A. Eur J Oral Sci 2005, 113, 417.

26. Sakaguchi, R. L.; Berge, H. X. J Dent 1998, 26, 695.

27. Stansbury, J. W.; Trujillo-Lemon, M.; Lu, H.; Ding, X. Z.; Lin, Y.; Ge, J. H. Dent Mater 2005, 21, 56.

28. Kim, Y. H. J Polym Sci Part A Polym Chem 1998, 36, 1685.

29. Voit, B. I. Acta Polym 1995, 46, 87.

30. Bosman, A. W.; Janssen, H. M.; Meijer, E. W. Chem Rev 1999, 99, 1665.

31. Frechet, J. M. J.; Hawker, C. J.; Gitsov, I.; Leon, J. W. J Macromol Sci Pure Appl Chem 1996, 33, 1399.

32. Jin, Y. H.; Cho, Y. H.; Schmidt, L. E.; Leterrier, Y.; Månson, J.A. E. J Micromech Microeng 2007, 17, 1147.

33. Schmidt, L. E.; Yi, S.; Jin, Y. H.; Leterrier, Y.; Cho, Y. H.; Månson, J.-A. E. J Micromech Microeng 2008, 18, 45022.

34. Turner, S. R.; Voit, B. I.; Mourey, T. H. Macromolecules 1993, 26, 4617.

35. Wang, S. J.; Fan, X. D.; Kong, J.; Liu, Y. Y. J Appl Polym Sci 2008, 107, 3812.

36. Magnusson, H.; Malmstrom, E.; Hult, A. Macromol Rapid Commun 1999, 20, 453.

37. Hoyle, C. E. In Radiation Curing: Science and Technology; Pappas, S. P., Ed.; Plenum Press: New York, 1992.

38. Anseth, K. S.; Wang, C. M.; Bowman, C. N. Polymer 1994, 35, 3243.

39. de Boer, J.; Visser, R. J.; Melis, G. P. Polymer 1992, 33, 1123.

40. Schmidt, L. E. Ph.D. Thesis, 3627, Ecole polytechnique fédérale de Lausanne, 2006.

41. Bowman, C. N.; Peppas, N. A. Macromolecules 1991, 24, 1914.

42. Frigerio, J. M. In La Couleur - Lumière, Vision et Matériaux; Elias, M., Lafait, J., Eds.; Belin: Paris, 2006.

43. Krogman, K. C.; Druffel, T.; Sunkara, M. K. In Proceedings of the 4th Topical Conference on Nanoscale Science and Engineering of the American Institute of Chemical Engineers, Austin, TX, November 7-12, 2004; p S338.

44. Caseri, W. Chem Eng Comm 2009, 196, 549.

45. Chandra, R.; Soni, R. K.; Murthy, S. S. Polym Int 1993, 31, 305.

46. Andrzejewska, E.; Bogacki, M. B.; Andrzejewski, M. Polimery 2001, 46, 549.

47. Chu, T. M. G.; Halloran, J. W. J Am Ceram Soc 2000, 83, 2375.

48. Kamal, M. R. Polym Eng Sci 1974, 14, 231. 
49. Timpe, H. J.; Strehmel, B. Macromol Chem Phys 1991, 192, 779 .

50. Timpe, H. J.; Strehmel, B.; Roch, F. H.; Fritzsche, K. Acta Polym 1987, 38, 238.

51. Andrzejewska, E.; Linden, L. A.; Rabek, J. F. Polym Int 1997, $42,179$.

52. Funke, W. Br Polym J 1989, 21, 107.

53. Nebioglu, A.; Soucek, M. D. J Polym Sci Part A Polym Chem 2006, 44, 6544 .
54. Patel, M. P.; Braden, M.; Davy, K. W. M. Biomater 1987, 8, 53.

55. Sangermano, M.; Ortiz, R. A.; Urbina, B. A. P.; Duarte, L. B.; Valdez, A. E. G.; Santos, R. G. Eur Polym J 2008, 44, 1046.

56. Hayek, A.; Xu, Y. G.; Okada, T.; Barlow, S.; Zhu, X. L.; Moon, J. H.; Marder, S. R.; Yang, S. J Mater Chem 2008, 18, 3316.

57. Austin, M. D.; Ge, H. X.; Wu, W.; Li, M. T.; Yu, Z. N.; Wasserman, D.; Lyon, S. A.; Chou, S. Y. Appl Phys Lett 2004, 84, 5299. 